\title{
Ovarian preservation in adenocarcinoma of the uterine cervix
}

Jiansong Zhou ${ }^{1 \dagger}$, Yuanyuan Chen ${ }^{2 \dagger}$, Ping Zhang ${ }^{3^{*}}$ and Hanmei Lou ${ }^{1^{*}}$

\begin{abstract}
Background: An upward trending incidence in cervical adenocarcinoma (ADC) has been reported in many countries. Because non-squamous histology has been associated with increased risk of ovarian metastases (OM), bilateral oophorectomy is commonly performed for ADC without due consideration for ovarian preservation, degrading the quality of life for young premenopausal patients.

Methods: Subjects were patients with International Federation of Gynecology and Obstetrics (FIGO) stage I-IIB cervical ADC who underwent radical hysterectomy, including pelvic lymphadenectomy and bilateral salpingo-oophorectomy at our institution between Oct. 2006 and Sept. 2014. Clinicopathologic variables were studied by univariate and multivariate analyses.

Results: Of the 312 patients enrolled in the study, 14 patients (4.5\%) developed OM. Multivariate analysis revealed that uterine corpus involvement (odds ratio [OR] 5.178, $p=0.019$ ), parametrial involvement (OR 14.125, $p=0.005$ ) and vaginal infiltration (OR 4.167, $p=0.047$ ) were independently associated with metastasis. OM had no effect on either relapse-free survival (95\% confidence interval [Cl]: 0.077-4.095, $p=0.57$ ) or overall survival (95\% Cl: 0.893-9.820, $p=0.076$ ).

Conclusion: Cervical ADC is associated with an increased risk of OM. Ovarian preservation surgery in cervical ADC may be safe for young patients at an early FIGO stage without deep stromal, endometrial or perineural invasion, and particularly without uterine corpus invasion, parametrial involvement and infiltration into the vagina.
\end{abstract}

Keywords: Adenocarcinoma, Ovarian metastasis, Ovarian preservation

\section{Background}

Invasive cervical cancer (ICC) ranks as the third most common malignancy and is the fourth leading cause of female cancer deaths worldwide [1]. Patients with FIGO early stage disease generally undergo radical hysterectomy and pelvic lymphadenectomy. However, bilateral oophorectomy is not part of standard surgical management of ICC.

Currently, an upward trend in the incidence of adenocarcinoma (ADC) has been reported in many countries, particularly among women under the age of 40 [2-5]. Since Shimada et al. and Ronnett et al. have reported that approximately $5 \%$ of women with cervical ADC are

\footnotetext{
*Correspondence: zhangping@zjcc.org.cn; louhm@zjcc.org.cn

${ }^{\dagger}$ Equal contributors

${ }^{3}$ Department of Gynecologic Oncology, Zhejiang Cancer Hospital, Hangzhou,

Zhejiang, People's Republic of China

${ }^{1}$ The Key Laboratory of Radiation Oncology of Zhejiang Province,

Department of Gynecologic Radiation Oncology, Zhejiang Cancer Hospital,

Hangzhou, Zhejiang, People's Republic of China

Full list of author information is available at the end of the article
}

at an increased risk of ovarian metastases (OM), which occurs in about half of ADC cases post-hysterectomy [6,7], oophorectomy is commonly performed in ADC to preclude OM.

Ovarian preservation, which is beneficial to the physiologic and psychosexual well-being of premenopausal women affected by cervical cancer, remains a challenge in clinical practice. Some believe that non-squamous histology should be a deterrent to ovarian transposition [8]. Others advocate lymphovascular space invasion (LVSI), deep stromal invasion (DSI) and uterine corpus involvement as contraindications $[8,9]$. The aim of the present retrospective study was to identify the clinicopathological factors associated with OM in ADC.

\section{Methods \\ Patients}

Study participants were patients diagnosed with FIGO stage I-IIB invasive ADC of the uterine cervix and 
treated by radical hysterectomy, bilateral salpingooophorectomy and pelvic lymphadenectomy at the Zhejiang Cancer Hospital, Zhejiang Province, China between Oct. 2006 and Sep. 2014. Clinical data were extracted from the institution's electronic databases after informed consent was obtained from all patients. The Medical Ethics Committee of Zhejiang Cancer Hospital approved the study.

The following clinical and histological parameters were evaluated in relation to OM: age at surgery, FIGO stage, bulky tumor size $(>4 \mathrm{~cm})$, differentiation, morphology, DSI ( $\geq 2 / 3)$, LVSI, parametrial involvement, uterine corpus involvement, endometrial invasion, fallopian tube invasion, vaginal infiltration, perineural invasion (PNI) and para-aortic/pelvic lymph node status.

\section{Statistical analysis}

Statistical analyses were performed with the SPSS 16.0 software package (IBM, Armonk, NY, USA). P-values $<0.05$ were considered statistically significant. Summary statistics are presented as frequencies and percentages. The Pearson $\chi^{2}$ test was used to assess the association between clinicopathologic parameters and the presence of OM. Multivariate analysis was used to detect independent risk factors for $\mathrm{OM}$ and results are presented as odds ratios (OR).

\section{Results}

\section{Patient characteristics}

A total of 312 ADC patients were enrolled into the study, including 9 patients (2.9\%) with FIGO stage IA, 217 patients $(69.6 \%)$ with stage IB, 74 patients $(23.7 \%)$ with stage
IIA and 12 patients (3.8\%) with stage IIB. The median age of patients was 46 years (range: 19-73 years).

OM were diagnosed in 14 patients (4.5\%). A summary of patients with OM is shown in Table 1. OM occurred in five of the 217 patients $(2.3 \%)$ in stage IB, eight of the 74 patients $(10.8 \%)$ in stage IIA and one of the 12 patients $(8.3 \%)$ in stage IIB. A significantly higher incidence of OM was observed in stage II ADC ( $p=0.002$, OR 9.899). The mean age of these 14 patients was 46 (range 32-68) years. Potential risk factors for $\mathrm{OM}$ are listed in Table 2. Patients with $\mathrm{OM}$ were frequently observed by univariate analysis with FIGO stage I or II $(p=0.002)$, DSI $(p=0.002)$, uterine corpus involvement $(p<0.001)$, endometrial invasion $(p<0.001)$, parametrial involvement $(p<0.001)$, PNI $(p=0.011)$, fallopian tube invasion $(p<0.001)$ or vaginal infiltration $(p<0.001)$. However, outcomes for patients with OM did not correlate with age at surgery, bulky tumor size, differentiation, morphology, LVSI or lymph node metastasis.

Furthermore, multivariate analysis identified uterine corpus involvement (OR 5.178, $p=0.019$ ), parametrial involvement (OR 14.125, $p=0.005)$ and vaginal infiltration (OR 4.167, $p=0.047$ ) to be independently associated with OM. Meanwhile, OM had no effect on either relapse-free survival (95\% confidence interval [CI]: $0.077-4.095, p=0.57)$ or overall survival $(95 \% \mathrm{CI}$ : 0.893-9.820, $p=0.076$ ) (Fig. 1).

\section{Discussion}

ICC is still a leading cause of cancer-related deaths in women worldwide. For decades, an upward trending

Table 1 Summary of patients with ovarian metastasis

\begin{tabular}{|c|c|c|c|c|c|c|c|c|c|c|c|c|c|}
\hline \multirow[t]{2}{*}{ Case } & \multirow[t]{2}{*}{ Age } & \multirow{2}{*}{$\begin{array}{l}\text { FIGO } \\
\text { stage }\end{array}$} & \multirow[t]{2}{*}{ Grade } & \multirow[t]{2}{*}{ DSI } & \multirow[t]{2}{*}{ Morphology } & \multirow[t]{2}{*}{$\mathrm{UCl}$} & \multirow{2}{*}{$\begin{array}{l}\text { Endometrial } \\
\text { invasion }\end{array}$} & \multirow{2}{*}{$\begin{array}{l}\text { Fallopian tube } \\
\text { invasion }\end{array}$} & \multirow{2}{*}{$\begin{array}{l}\text { Perineural } \\
\text { invasion }\end{array}$} & \multirow[t]{2}{*}{ LVSI } & \multirow{2}{*}{$\begin{array}{l}\text { Infiltration } \\
\text { to vagina }\end{array}$} & \multicolumn{2}{|c|}{ Lymph node metastasis } \\
\hline & & & & & & & & & & & & Para-aortic & Pelvic \\
\hline 1 & 42 & $\| A$ & G3 & + & Endophytic & + & - & - & + & + & - & + & + \\
\hline 2 & 43 & $\| A$ & G2 & + & Exophytic & - & - & - & + & - & + & - & - \\
\hline 3 & 62 & $\| A$ & G2 & + & Endophytic & + & - & - & + & - & + & - & + \\
\hline 4 & 49 & $\mathrm{IB}$ & G3 & + & Exophytic & + & - & + & - & + & + & - & - \\
\hline 5 & 41 & $\| A$ & G2 & + & Exophytic & - & - & - & - & + & + & - & + \\
\hline 6 & 51 & $\| \mathrm{B}$ & G2 & + & Exophytic & - & - & - & - & - & - & - & - \\
\hline 7 & 36 & $\| A$ & G3 & - & Exophytic & + & + & - & - & - & - & - & - \\
\hline 8 & 55 & $\| A$ & G2 & & Exophytic & - & - & - & - & - & + & - & + \\
\hline 9 & 48 & $\| A$ & $\mathrm{G} 2$ & & Endophytic & - & - & - & + & + & + & - & - \\
\hline 10 & 36 & $\mathrm{IB}$ & G3 & - & Exophytic & + & - & - & - & - & - & - & - \\
\hline 11 & 43 & $\mathrm{IB}$ & $\mathrm{G} 2$ & - & Exophytic & + & - & - & - & - & + & - & - \\
\hline 12 & 68 & $\mathrm{IB}$ & G3 & - & Endophytic & + & + & + & - & + & + & - & - \\
\hline 13 & 43 & $\| A$ & $\mathrm{G} 2$ & + & Endophytic & + & + & + & + & + & - & - & - \\
\hline 14 & 32 & $\mid \mathrm{B}$ & G3 & + & Endophytic & + & - & + & - & + & - & - & - \\
\hline
\end{tabular}

DSI deep stromal invasion

$\mathrm{UCl}$ uterine corpus involvement

LVSI lymphovascular space invasion 
Table 2 Univariate and multivariate analyses of risk factors for ovarian metastasis in patients with cervical adenocarcinoma

\begin{tabular}{|c|c|c|c|c|c|c|}
\hline \multirow{3}{*}{$\begin{array}{l}\text { Parameter } \\
\text { Total no. of patients enrolled }\end{array}$} & \multirow{3}{*}{$\begin{array}{l}N(\%) \\
312\end{array}$} & \multirow{2}{*}{\multicolumn{3}{|c|}{$\begin{array}{l}\text { Univariate analyses } \\
\text { Ovarian metastasis }\end{array}$}} & \multicolumn{2}{|c|}{ Multivariate analyses } \\
\hline & & & & & \multirow[t]{2}{*}{ Odds ratio } & \multirow[t]{2}{*}{$p$-value } \\
\hline & & Yes & No & $p$-value & & \\
\hline \multicolumn{7}{|l|}{ Age at surgery } \\
\hline$<60$ & $282(90.4)$ & 12 & 270 & 0.544 & & \\
\hline$\geq 60$ & $30(9.6)$ & 2 & 28 & & & \\
\hline \multicolumn{7}{|l|}{ FIGO stage } \\
\hline I & $226(72.4)$ & 5 & 221 & $0.002^{*}$ & 2.445 & 0.243 \\
\hline$\|$ & $86(27.6)$ & 9 & 77 & & & \\
\hline \multicolumn{7}{|l|}{ Tumor diameter $(\mathrm{cm})$} \\
\hline$<4$ & $221(70.8)$ & 7 & 214 & 0.079 & & \\
\hline$\geq 4$ & $91(29.2)$ & 7 & 84 & & & \\
\hline \multicolumn{7}{|l|}{ Differentiation } \\
\hline $\mathrm{G} 1+\mathrm{G} 2$ & $191(61.2)$ & 8 & 182 & 0.756 & & \\
\hline G3 & $121(38.8)$ & 6 & 115 & & & \\
\hline \multicolumn{7}{|l|}{ Tumour morphology } \\
\hline Exophytic & $109(34.9)$ & 8 & 101 & 0.075 & & \\
\hline Endophytic & $203(65.1)$ & 6 & 197 & & & \\
\hline \multicolumn{7}{|l|}{ Deep stromal invasion } \\
\hline Superficial $(<2 / 3)$ & $210(67.3)$ & 4 & 206 & $0.002^{*}$ & 1.307 & 0.743 \\
\hline Deep $(\geq 2 / 3)$ & $102(32.7)$ & 10 & 92 & & & \\
\hline \multicolumn{7}{|l|}{ Parametrial invasion } \\
\hline Negative & $296(94.9)$ & 8 & 288 & $5.80 \mathrm{E}-11^{*}$ & 14.125 & $0.005^{*}$ \\
\hline Positive & $16(5.1)$ & 6 & 10 & & & \\
\hline \multicolumn{7}{|l|}{ Lymph-vascular space invasion } \\
\hline Negative & $197(63.1)$ & 7 & 190 & 0.297 & & \\
\hline Positive & $115(36.9)$ & 7 & 108 & & & \\
\hline \multicolumn{7}{|l|}{ Pelvic node status } \\
\hline Negative & $227(72.8)$ & 10 & 217 & 0.909 & & \\
\hline Positive & $85(27.2)$ & 4 & 81 & & & \\
\hline \multicolumn{7}{|l|}{ Fallopian tube invasion } \\
\hline Negative & $302(96.8)$ & 10 & 292 & $3.51 \mathrm{E}-8^{*}$ & 1.837 & 0.338 \\
\hline Positive & $10(3.2)$ & 4 & 6 & & & \\
\hline \multicolumn{7}{|l|}{ Para-aortic node status } \\
\hline Negative & $305(97.8)$ & 13 & 292 & 0.205 & & \\
\hline Positive & $7(2.2)$ & 1 & 6 & & & \\
\hline \multicolumn{7}{|l|}{ Infiltration to vagina } \\
\hline Yes & $58(18.6)$ & 8 & 50 & $1.48 \mathrm{E}-4^{*}$ & 4.167 & $0.047^{*}$ \\
\hline No & $254(81.4)$ & 6 & 248 & & & \\
\hline \multicolumn{7}{|l|}{ Endometrial invasion } \\
\hline Negative & $300(96.2)$ & 11 & 289 & $4.65 \mathrm{E}-4^{*}$ & 3.156 & 0.213 \\
\hline Positive & $12(3.8)$ & 3 & 9 & & & \\
\hline \multicolumn{7}{|l|}{ Uterine corpus invasion } \\
\hline Negative & $252(80.8)$ & 5 & 247 & $1.20 \mathrm{E}-5^{*}$ & 5.178 & $0.019^{*}$ \\
\hline Positive & 60 (19.2) & 9 & 51 & & & \\
\hline
\end{tabular}


Table 2 Univariate and multivariate analyses of risk factors for ovarian metastasis in patients with cervical adenocarcinoma (Continued)

\begin{tabular}{llllll}
\hline Perineural invasion & & & & & \\
Negative & $271(86.9)$ & 9 & 362 & $0.011^{*}$ & 0.273 \\
Positive & $41(13.1)$ & 5 & 36 & & 0.174 \\
\hline
\end{tabular}

incidence of ADC has been reported in many countries, accounting for approximately one-quarter of all ICC cases [10]. ADC is distinguished from squamous cell carcinoma (SCC) by virtue of different human papillomavirus types, patterns of spread, prognosis and recurrence $[11,12]$. Furthermore, published data has revealed that the incidence of $\mathrm{OM}$ in the presence of nonsquamous histology is increased compared to SCC [8]; hence, bilateral oophorectomy is frequently recommended in cases of ADC.

Approximately $50 \%$ of ICC patients are premenopausal and under 45 years old [13]. Ovarian preservation has proven invaluable for improving the quality of life of these young women. According to the literature, ovarian metastatic incidence occurs more frequently among patients with ADC than in those with SCC, ranging between $1.7 \%$ and $18.9 \%$ and from $0.4 \%$ to $1.3 \%$, respectively $[6,8,14,15]$. Moreover, Ronnett et al. reported that in about half of ADC cases, metastases occurred posthysterectomy [7]. Therefore, the benefits of preserving hormonal function may be offset by a potentially higher risk of recurrence in ADC. Conversely, Gubbala et al. concluded that ovarian transposition resulted in significant preservation of ovarian function with negligible risk of metastases to the transposed ovaries despite the common

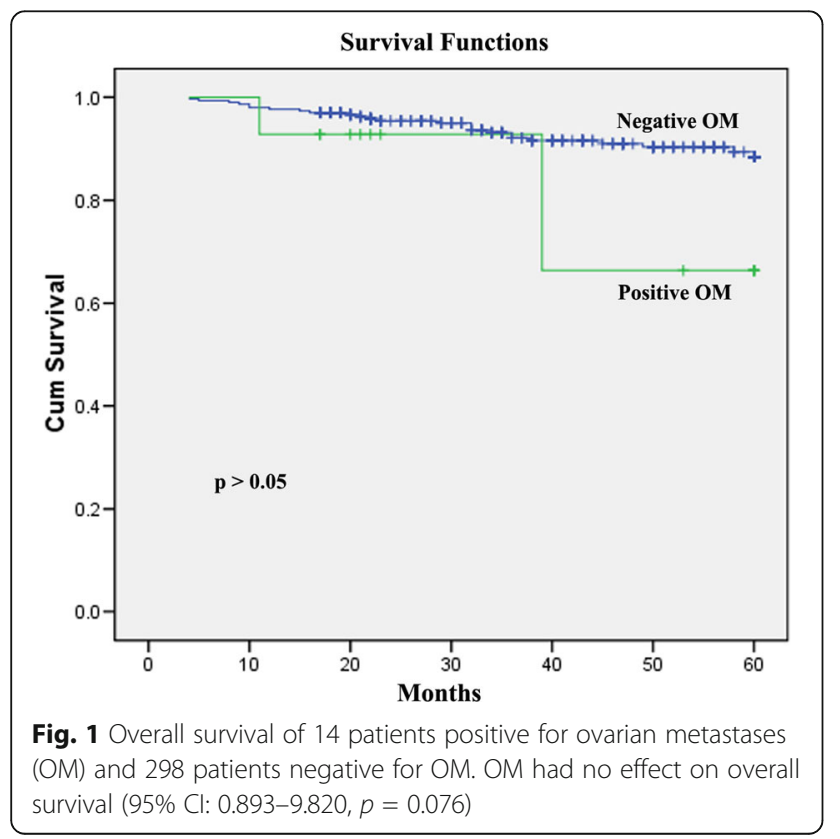

incidence of ovarian cysts [16]. Lyu et al. found that ovarian preservation provided oncological safety for young women with stage I cervical adenocarcinoma [17]. In the present study, the incidence of OM in ADC was 4.5\% (14/ 312 ), and a significantly higher incidence of OM was observed in stage II compared to stage I cancers.

The selection of premenopausal patients who would benefit from ovarian preservation to improve the quality of life is challenging. A thorough understanding of the risk factors involved would be of great value for following a patient with ovarian preservation postoperatively [17]. The majority of cases we have examined have been diagnosed through primary radical surgery with bilateral oophorectomy. However, in the past two decades, increasing attention has been paid to $\mathrm{OM}$ and contributing factors. Age, FIGO stage, histology, lymph node metastases, DSI, LVSI, bulky tumor size, parametrial invasion and corpus uteri invasion have been determined to be independent risk factors for OM in ADC [8, 18-21]. In our study, we identified FIGO stage, DSI, uterine corpus invasion, endometrial invasion, parametrial involvement, PNI, fallopian tube invasion and vaginal infiltration as significantly related to $\mathrm{OM}$ in $\mathrm{ADC}$. In our multivariate analysis, uterine corpus invasion, parametrial involvement and vaginal infiltration were independent risk or protective factors for $\mathrm{OM}$ in patients with ADC. The occurrence of OM had no significant relationship to either relapse-free survival or overall survival.

The routes by which ICC spreads to the ovary remain unclear. Wu et al. proposed that lymphatic spread and transtubal implantation may be possible pathways of metastases from the cervix to the ovaries [18]. Tabata et al. reported that $\mathrm{OM}$ may take place via hematogenous spread of cervical carcinoma [22]. Further research efforts will be required to establish the pathways involved.

\section{Conclusions}

In conclusion, we found that cervical ADC is associated with a relatively higher risk of OM. Based on our data, we suggest that ovarian preservation may be safely performed in young patients with early FIGO stage cervical ADC without deep stromal invasion, endometrial invasion or perineural invasion, and particularly in the absence of uterine corpus invasion, parametrial involvement and infiltration to the vagina. 


\section{Abbreviations}

ADC: Adenocarcinoma; DSI: Deep stromal invasion; ICC: Invasive cervical cancer; LVSI: Lymphovascular space invasion; OM: Ovarian metastases; PNI: Perineural invasion; SCC: Squamous cell carcinoma

\section{Acknowledgements}

Not applicable.

\section{Funding}

The Zhejiang Province Nature Foundation (grant No. LQ16H160016).

\section{Availability of data and materials}

Please contact the corresponding author for data requests.

\section{Authors' contributions}

PZ and HL participated in the study design, and critically appraised and revised the manuscript. JZ conducted the literature search, extracted the data, drafted the manuscript and participated in data analysis. YC performed data analysis and revised the manuscript. All authors read and approved the final manuscript.

\section{Ethics approval and consent to participate}

The Local Institutional Ethics Committee approved the study, and informed consent for publication was obtained from all patients.

\section{Competing interests}

The authors declare that they have no competing interests.

\section{Publisher's Note}

Springer Nature remains neutral with regard to jurisdictional claims in published maps and institutional affiliations.

\section{Author details}

${ }^{1}$ The Key Laboratory of Radiation Oncology of Zhejiang Province, Department of Gynecologic Radiation Oncology, Zhejiang Cancer Hospital, Hangzhou, Zhejiang, People's Republic of China. 'Department of Radiation Oncology, Hangzhou Cancer Hospital, Hangzhou, Zhejiang, People's Republic of China. ${ }^{3}$ Department of Gynecologic Oncology, Zhejiang Cancer Hospital, Hangzhou, Zhejiang, People's Republic of China.

Received: 9 September 2016 Accepted: 16 June 2017

Published online: 24 July 2017

\section{References}

1. Jemal A, Bray F, Center MM, Ferlay J, Ward E, Forman D. Global cancer statistics. CA Cancer J Clin. 2011;61:69-90.

2. Smith HO, Tiffany MF, Qualls CR, Key CR. The rising incidence of adenocarcinoma relative to squamous cell carcinoma of the United States-a 24-year population-based study. Gynecol Oncol. 2000;78:97-105.

3. Vizcaino AP, Moreno V, Bosch FX, Muñoz N, Barros-Dios XM, Borras J, et al. International trends in incidence of cervical cancer: II. Squamous-cell carcinoma. Int J Cancer. 2000;86:429-35.

4. Visioli CB, Zappa M, Ciatto S, lossa A, Crocetti E. Increasing trends of cervical adenocarcinoma incidence in Central Italy despite Extensive Screening Programme, 1985-2000. Cancer Detect Prev. 2004;28:461-4.

5. Bray F, Carstensen B, Møller H, Zappa M, Zakelj MP, Lawrence G, et al. Incidence trends of adenocarcinoma of the cervix in 13 European countries. Cancer Epidemiol Biomark Prev. 2005;4:2191-9.

6. Shimada M, Kigawa J, Nishimura R, Yamaguchi S, Kuzuya K, Nakanishi T, et al. Ovarian metastasis in carcinoma of the uterine cervix. Gynecol Oncol. 2006:101:234-7.

7. Ronnett BM, Yemelyanova AV, Vang R, Gilks CB, Miller D, Gravitt PE, et al. Endocervical adenocarcinomas with ovarian metastases: analysis of 29 cases with emphasis on minimally invasive cervical tumours and the ability of the metastases to simulate primary ovarian neoplasms. Am J Surg Pathol. 2008;32:1835-53.

8. Landoni F, Zanagnolo V, Lovato-Diaz L, Maneo A, Rossi R, Gadducci A, et al. Ovarian metastases in early-stage cervical cancer (IA2-IIA): a multicenter retrospective study of 1965 patients (a Cooperative Task Force study). Int J Gynecol Cancer. 2007;17:623-8.
9. Morice P, Haie-Meder C, Pautier P, Lhomme C, Castaigne D. Ovarian metastasis on transposed ovary in patients treated for squamous cell carcinoma of the uterine cervix: report of two cases and surgical implications. Gynecol Oncol. 2001:83:605-7.

10. Parkin DM, Bray F. Chapter 2: The burden of HPV-related cancers. Vaccine. 2006;24(Suppl. 3):S11-25.

11. Fujiwara H, Yokota H, Monk B, Treilleux I, Devouassoux-Shisheboran M, Davis A, et al. Gynecologic Cancer InterGroup (GCIG) Consensus Review for Cervical Adenocarcinoma. Int J Gynecol Cancer. 2014;24(9 Suppl 3):S96-101.

12. Irie T, Kigawa J, Minagawa $Y$, Itamochi H, Sato S, Akeshima R, et al. Prognosis and clinicopathological characteristics of IB-IIB adenocarcinoma of the uterine cervix in patients who have had radical hysterectomy. Eur J Surg Oncol. 2000;26:464-7.

13. Winarto H, Febia E, Purwoto G, Nuranna L. The Need for Laparoscopic Ovarian Transposition in Young Patients with Cervical Cancer Undergoing Radiotherapy. Int J Reprod Med. 2013;2013:173568. Epub 2013 Dec 3

14. Kim MJ, Chung HH, Kim JW, Park NH, Song YS, Kang SB. Uterine corpus involvement as well as histologic type is an independent predictor of ovarian metastasis in uterine cervical cancer. J Gynecol Oncol. 2008;19:181-4.

15. Natsume N, Aoki Y, Kase H, Kashima K, Sugaya S, Tanaka K. Ovarian Metastasis in Stage IB and II Cervical Adenocarcinoma. Gynecol Oncol. 1999;74:255-8.

16. Gubbala K, Laios A, Gallos I, Pathiraja P, Haldar K, Ind T. Outcomes of ovarian transposition in gynaecological cancers; a systematic review and meta-analysis. J Ovarian Res. 2014;7:69. eCollection 2014

17. Lyu J, Sun T, Tan X. Ovarian Preservation in Young Patients With Stage I Cervical Adenocarcinoma. Int J Gynecol Cancer. 2014;24:1513-20.

18. Wu HS, Yen MS, Lai CR, Ng HT. Ovarian metastasis from cervical carcinoma. Int J Gynaecol Obstet. 1997:57:173-8.

19. Yamamoto R, Okamoto K, Yukiharu T, Kaneuchi M, Negishi H, Sakuragi N, et al. A study of risk factors for ovarian metastases in stage Ib-IIlb cervical carcinoma and analysis of ovarian function after a transposition. Gynecol Oncol. 2001;82:312-6.

20. Sakuragi N, Takeda N, Hareyama H, Fujimoto T, Todo Y, Okamoto K, et al. A multivariate analysis of blood vessel and lymph vessel invasion as predictors of ovarian and lymph node metastases in patients with cervical carcinoma. Cancer. 2000;88:2578-83.

21. Hu T, Wu L, Xing H, Yang R, Li X, Huang $K$, et al. Development of Criteria for Ovarian Preservation in Cervical Cancer Patients Treated with Radical Surgery With or Without Neoadjuvant Chemotherapy: A Multicenter Retrospective Study and Meta-analysis. Ann Surg Oncol. 2013;20:881-90. Epub 2012 Oct 3

22. Tabata M, Ichinoe $K$, Sakuragi N, Shiina Y, Yamaguchi T, Mabuchi Y. Incidence of ovarian metastasis in patients with cancer of the uterine cervix. Gynecol Oncol. 1987:28:255-61.

\section{Submit your next manuscript to BioMed Central and we will help you at every step:}

- We accept pre-submission inquiries

- Our selector tool helps you to find the most relevant journal

- We provide round the clock customer support

- Convenient online submission

- Thorough peer review

- Inclusion in PubMed and all major indexing services

- Maximum visibility for your research

Submit your manuscript at www.biomedcentral.com/submit
C Biomed Central 